\title{
PENGARUH BRAND IMAGE TERHADAP LOYALITAS MEREK, BRAND AWARENESS, PERSEPSI KUALITAS DAN ASSOSIASI MEREK
}

\author{
Rahmaddian
}

\begin{abstract}
ABSTRAK
Perguruan tinggi yang tumbuh kembang banyak diminati di Indonesia karena popularitas dan prestigenya dan berasosiasi perguruan tinggi negeri hanya bagi mereka yang cerdas sehingga persaingan untuk masuk ke PT negeri sangatlah ketat. Diterbitkanya Permendikbud no.24 tahun 2012 tentang penyelenggaraan pendidikan jarak jauh pada Perguruan Tinggi membuka kesempatan dan peluang bagi Perguruan Tinggi lain selain untuk berkompetisi menyelenggarakan pendidikan jarak jauh. Hal ini merupakan tantangan bagi PTJJ yang telah ada. Realita ini mengharuskan PJJ untuk meningkatkan kuantitas dan layanannya. Dalam manajemen pemasaran terdapat berbagai strategi yang dapat diterapkan untuk menjaga siklus daur hidup suatu organisasi dalam menghadapi para pesaing termasuk Universitas Terbuka pendiri PJJ, salah satunya adalah dengan memperhatikan atribut-atribut pada organisasai tersebut.

Tujuan penelitian ini adalah 1) Mengetahui tingkat signifikansi masingmasing elemen dari variabel brand equity, 2) Mengetahui rangkaian program promosi yang sudah dijalankan dalam membentuk image 3) Untuk mengetahui meningkatkan loyalitas pelanggan. Hasil Penelitian dan Kesimpulan serta Saran ini menunjukan adanya H1 Pengaruh Brand Image terhadap BA sebesar 12.745171, , H2 BI berpengaruh signifikan terhadap Asosiasi Berdasarkan nilai tstatistik 10.715180, H3 Brand image berpengaruh signifikan terhadap Kualitas Berdasarkan t-statistik 9.865272,. H4 Pengaruh BI terhadap Loyalitas sebesar 5.646275, nilai diatas lebih besar dari nilai t-tabel 1,98 untuk level signifikan 0.05 (5\%). Brand image UT dimata mahasiswa mudah di ingat terutama logo UT namun untuk yang bukan pelanggan tidak tahu mengerti tentang logo tersebut. Loyalitas dari suatu merek merupakan gambaran dari keterkaitan pelanggan dalam sebuah merek, ukuran tersebut dapat mempengaruhi pemikiran konsumen untuk dalam pemilihan produk atau jasa. Brand UT hanya membenak kepada mahsiswa saja perlu di ada inovasi-inovasi untuk dapat memperkenalkan UT sampai kepelosok-pelosok begitu juga brand awareness UT dari sisi layanan yang terkomputerisasi yang banyak mengalami kendala jaringan dan dibutuhkan kerjasama dengan vendor-vendor dibidang IT untuk memperkuat jaringan internet sampai ketingkat pedesaan.
\end{abstract}

Kata Kunci: Loyalitas, Brand Awareness, persepsi Kualitas, Asosiasi Merek

\section{PENDAHULUAN}

Meningkatnya perguruan tinggi di Indonesia di wilayah Kalimantan Tengah telah mendorong tingkat persaingan dalam merebut pangsa pasar semakin ketat. Berdasarkan data dari Kementerian Pendidikan dan Kebudayaan, pada tahun 2010 ada 3098 perguruan tinggi yang tersebar di seluruh Indonesia, dan di Kalteng sendiri ada 28 perguruan tinggi yang terus perkembangan seperti berikut ini : 


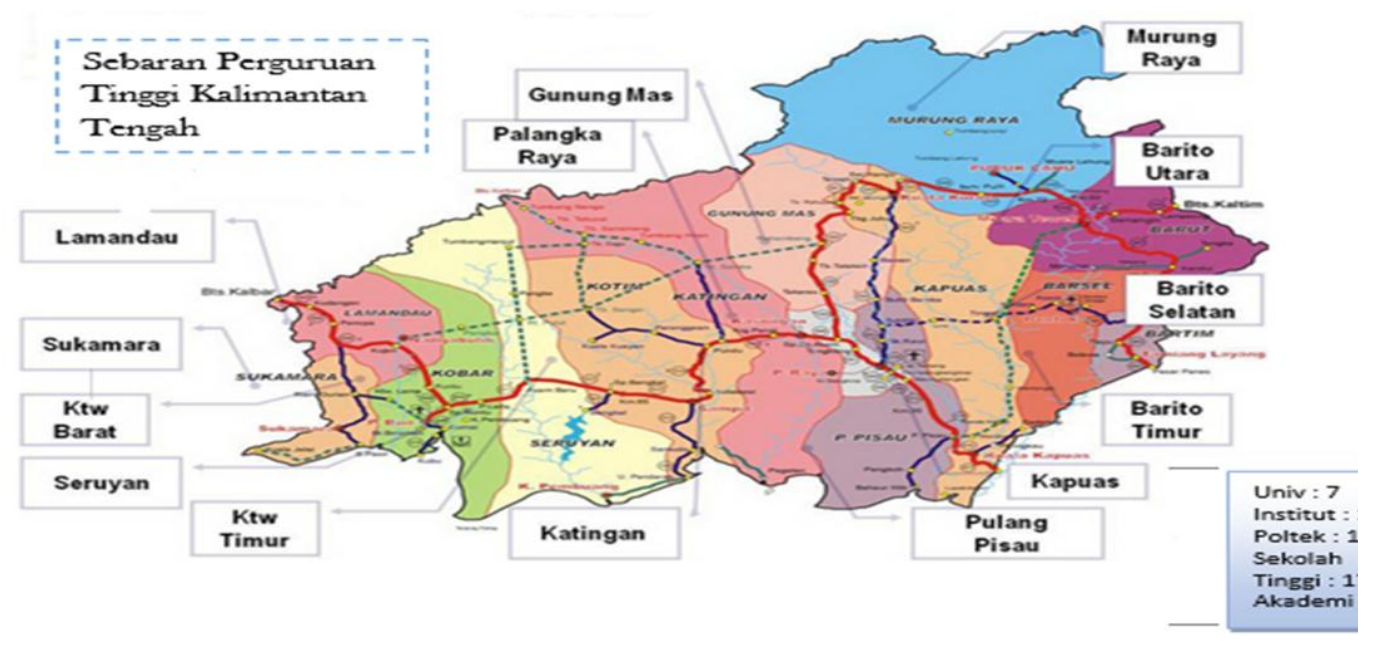

Persaingan antar perguruan tinggi tidak hanya dalam menarik calon mahasiswa akan tetapi juga mempertahankan mahasiswa yang ada. Kelangsungan hidup perguruan tinggi dipengaruhi oleh kemampuan dalam menciptakan keunggulan bersaing. Berdasarkan data, angka pelajar SLTA di Kalimantan tengah tahun 2015-2016 sebanyak 15.888 orang (Kemdikbud 2015-2016) dan jumlah tenaga kerja berjumlah 1.740 .381 orang (BPS Kalteng 2015) hal ini merupakan peluang bagi semua Perguruan Tinggi di Kalimantan tengah menanamkan citranya masing-masing untuk mendapatkan pangsa pasarnya dan magnet usia produktif pelajar. Asosasi UT tentang belajar mandiri sambil bekerja dan tidak mengenal umur merupakan peluang yang sangat besar untuk memperoleh kesempatan belajar semakin terbuka lebar. Dewasa ini telah terjadi persaingan citra antar perguruan tinggi untuk berusaha tampil lebih baik dari pesaing. Salah satu faktor yang dapat memperkuat citra positif organisasi pendidikan dimata masyarakat adalah melalui penciptaan citra positif dengan cara menciptakan citra positif adalah membangun ekuitas merek yang kuat.

Universitas Terbuka (UT) yang dikenal sebagai salah satu mega university menawarkan keunggulan sistem belajar jarak jauh (SBJJ) yang penekanannya pada fleksibilitas tinggi disesuaikan kebutuhan pengguna para guna dalam menghadapi situasi persaingan dengan institusi pendidikan lain yang menawarkan program dengan modus pendidikan jarak jauh. Selain itu, UT masih harus mempertahankan diri dalam kaitannya dengan kemampuan menawarkan pendidikan yang dapat menciptakan kesan positif dan berkualitas sehingga dapat masuk dalam jajaran perguruan tinggi unggulan lain yang ada di Indonesia. Berdasarkan uraian latar belakang diatas, maka peneliti dapat merumuskan masalah Bagaimana posisi ekuitas merek dari UT berdasarkan persepsi mahasiswa UT dan masyarakat luas, Bagaimana pengukuran ekuitas merek UT. Tujuan Penelitian melakukan analisa dimensi kesadaran, assosiasi, persepsi kualitas/kepemimpinan, loyalitas, dan perilaku pasar berdasarkan penilaian mahasiswa UT dan masyarakat luas, mengevaluasi ekuitas merek UT berdasarkan model brand equity. 


\section{TINJAUAN PUSTAKA}

Menurut American Marketing Assiciation definisi brand (merek) adalah nama, istilah, tanda, simbol atau rancangan, atau kombinasi hal-hal tersebut yang dimaksud untuk mengidentifikasikan produk atau jasa yang dihasilkan sehingga berbeda dari produk atau jasa yang dihasilkan pesaing (Kotler dan Keller 2007). Merek juga dapat dipatenkan agar dapat terlindung dari upaya pemalsuan dan pembajakan. Merek berbeda dengan produk. Produk adalah sesuatu yang dihasilkan oleh pabrik, sedangkan merek sesuatu yang dibeli oleh konsumen. Produk boleh saja mati, namun tidak demikian dengan merek. Dengan demikian, citra merek dapat menurun maka diperlukan revitalisasi. Proses penurunan citra dapat saja terjadi karena proses daur hidup (product life cycle), setiap produk atau merek mengalami masa kedewasaan (maturity). Kesetiaan merek produk juga dapat mempengaruhi persepsi pelanggan yang lebih setia dan akan mengunggulakan serta mengarah dari merek tersebut sebagai nilai yang unggul dari sebuah penawaran lain. Kesetiaan merek memberikan nilai yang berharga dan strategis dalam potensi mengurangi biaya pemasaran, mempengaruhi Perdagangan dan kemampuan untuk menarik pelanggan baru (Kim 2006). Penciptaan merek harus dikembangkan waktu demi waktu, Untuk universitas dapat menciptakan merek yang efektif dalam menarik calon siswa (Garcia 2016).

\section{METODOLOGI}

Penelitian ini dilakukan untuk menganalisis elemen-elemen utama ekuitas merek pada Universitas Terbuka. Jenis data yang digunakan pada penelitian ada 2 (dua) jenis yaitu data primer dan data sekunder. Pertama, Data primer yaitu data penelitian yang diperoleh secara langsung dari sumber asli (tidak melalui sumber perantara) dan data dikumpulkan melalui kegiatan wawancara terstruktur dengan menggunakan kuesioner sebagai instrumen pengumpulan datanya. Bentuk pertanyaannya kombinasi antara pertanyaan tertutup dan terbuka. Kedua, data sekunder adalah data yang merupakan sumber data penelitian yang diperoleh peneliti secara tidak langsung melalui perantara (diperoleh dan dicatat oleh pihak lain). Jumlah populasi untuk penelitian yang yang digunakan dalam penelitian ini berdasarkan pendekatan jumlah mahasiswa UT di Kalimantan tengah masa registrasi 2005-2017, Teknik sampling yang digunakan adalah non probability sampling Yang pertama yaitu menentukan kuota dari anggota populasi.. Data sampel sebanyak 150 responden yang telah ditentukan, dikuotakan berdasarkan wilayah di Kalimantan tengah. skala pengukurannya menggunakan skala likert dengan 4 jenjang pilihan yaitu Sangat Tidak Setuju, Tidak Setuju, Setuju, Sangat, Setuju

\section{PEMBAHASAN}

Data grafik menyebutkan $30 \%$ lebih respopnden dari Faluktas Ekonomi, disusul oleh Fhisip sebanyak 28\% dan sisanya dari fakultas lain yaitu FKIP 26\% dan FMIPA 15\% saja. Dominasi gender diperkuat oleh laki-laki sebanyak 50.2\% dan 49 lainya perempuan.. Secara rata-rata jenis pekerjaan dari responden adalah 
pegawai swasta atau honorer dari sebuah instansi sebanyak 33\%, diikuti oleh wiraswasta 25\% lebih dilanjutkan dengan PNS 19.6\% dan sisanya lain-lain sebanyak $21 \%$. Terbanyak responden dalam penelitian ini adalah dari SLTA dan sederajat sebanyak 60\% dilanjutkan oleh diploma dari program ekstensi dan S1 serta Magister. Adapun usia yang mendominasi adalah usia produktif 21 sampai dengan 30 tahun $38 \%$ dan yang paling utama adalah mahasiswa dari program bidik misi sebanyak 39\% serta diikuti oleh usia 31-40 sebanyak 18\% dan adapula yang usia diatas 40 tahun.

\section{Analisis dengan Struktural Equation Modeling}

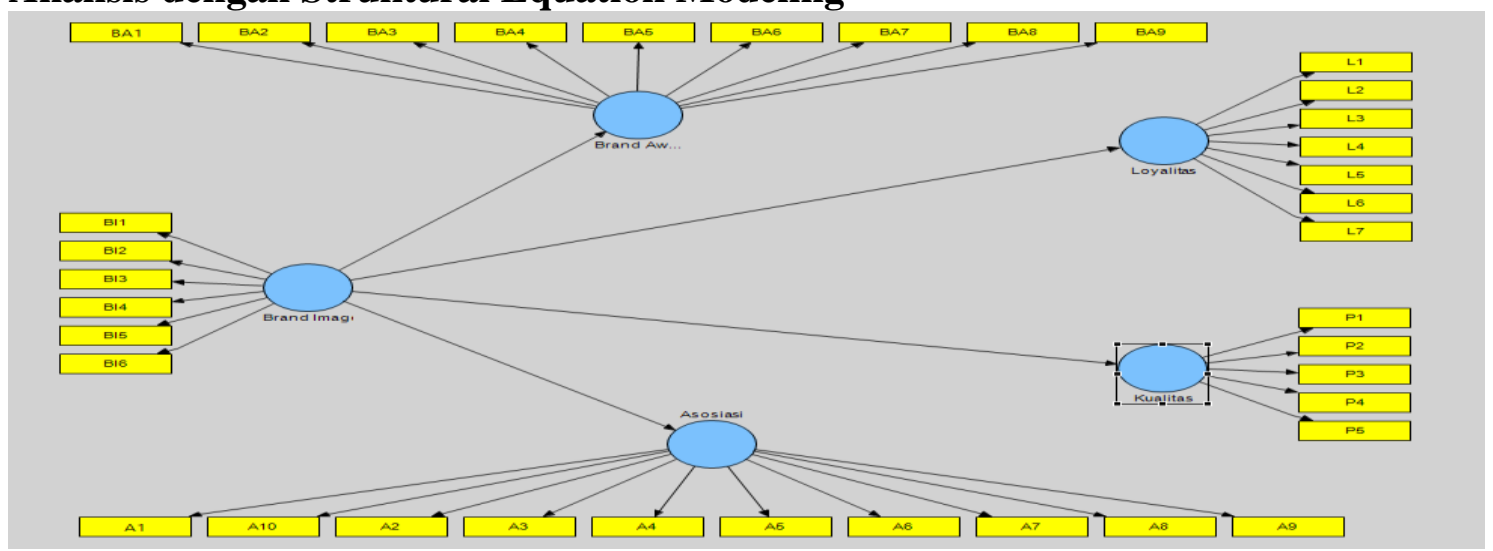

Pada tahap ini menggambarkan seluruh aktivitas variable dan indikator variabelnya berserta komponen-komponen yang terdiri dari variable endogen berupa ekuitas merek sebanyak 6 komponen, brand awaness 9 komponen, Loyalitas 7 komponen, Kualitas 5 Komponen dan Asosiasi sebanyak 10 komponen.

\section{Hasil pengukuran denga SEM Menilai Outer Model}

a. Convergent Validity 


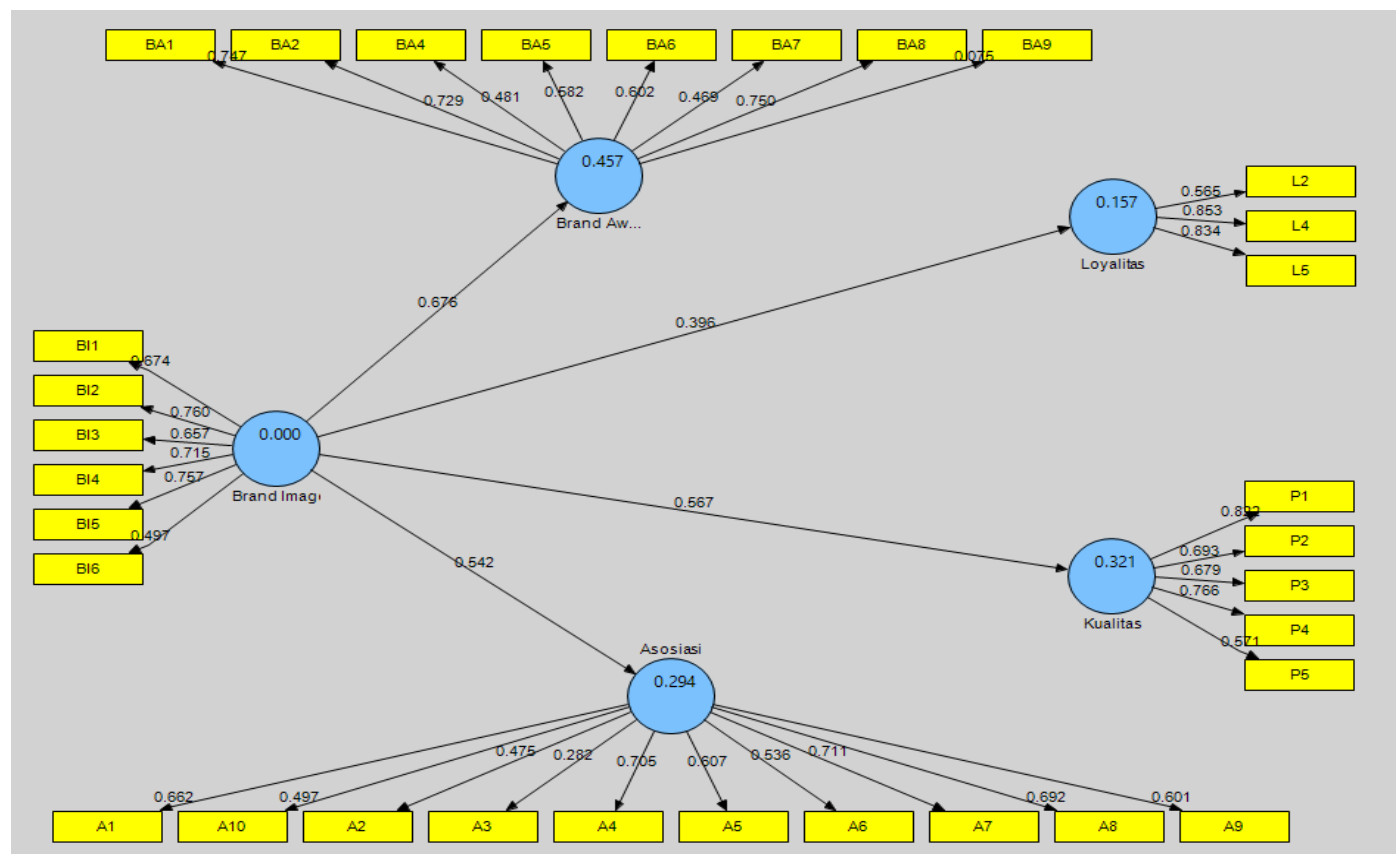

Dari hasil algoritma olah data yang dilakukan melalui uji dengan SEM menunjukan bahwa tidak ada indicator yang kurang dari 0.4 ini berarti tidak ada komponen atau indikator yang disisihkan atau didrop dari indikator utamanya. Hal ini sejalan dengan apabila suatu outer loading dapat dikatakan baik apabila adalah jika outer loadingnya diatas 0.70 sedangkan ambang batas 0.50 adalah batas tolelir dan dibawah 0,40 akan dikeluarkan atau didrop dari analisis (Ghojali 2015). Adapun indikatornya adalah BA3 "Layanan cepat dan terkomputerisasi", L1 "Selalu ingin Registrasi ulang semester berikutnya", L3 "Tidak ragu dengan UT", L6 "Tidak terpengaruh terhadap biaya" dan L7 "Tetap pilih UT sebagai unggulan dibanding kampus lain "dibuang karena kurang dari 0.4.

Nilai Discriminant Validity (Cross Loading)

\begin{tabular}{|c|c|c|c|c|c|}
\hline & Asosiasi & Brand Awarness & Brand Image & Kualitas & Loyalitas \\
\hline A4 & 0.704774 & 0.183979 & 0.335925 & 0.291526 & 0.313374 \\
\hline A7 & 0.710987 & 0.080469 & 0.265951 & 0.198113 & 0.351511 \\
\hline A8 & 0.692120 & 0.110420 & 0.219165 & 0.184952 & 0.343752 \\
\hline BA1 & 0.179487 & 0.747017 & 0.486649 & 0.192236 & 0.241154 \\
\hline BA2 & 0.467335 & 0.729399 & 0.536476 & 0.399292 & 0.398655 \\
\hline BA6 & -0.003215 & 0.602183 & 0.402031 & 0.130165 & 0.084994 \\
\hline BI1 & 0.245699 & 0.307395 & 0.674121 & 0.290909 & 0.257356 \\
\hline BI2 & 0.368850 & 0.548732 & 0.759854 & 0.320965 & 0.399969 \\
\hline BI3 & 0.402326 & 0.317474 & 0.656564 & 0.465245 & 0.323249 \\
\hline
\end{tabular}




\begin{tabular}{|l|l|l|l|l|l|}
\hline L4 & 0.298373 & 0.331127 & 0.351674 & 0.302561 & 0.853005 \\
\hline L5 & 0.398807 & 0.445723 & 0.346758 & 0.359765 & 0.833553 \\
\hline P1 & 0.472393 & 0.259843 & 0.429577 & 0.822121 & 0.298698 \\
\hline P3 & 0.431951 & 0.323183 & 0.349936 & 0.679339 & 0.441930 \\
\hline P4 & 0.287627 & 0.356324 & 0.472420 & 0.765981 & 0.346175 \\
\hline
\end{tabular}

Discriminant validity digunakan untuk memastikan bahwa setiap konsep dari variabel laten/konstruk berbeda dengan variabel laten lainnya antara lain ekuitas merek dan yang lain mempunyai kesamaan antara lain loyalitas, asosiasi, Brand Awarness, dan kualitas adalah pada Asosiasi Merek A6 0.831202 "Kuliah sambil kerja".A4 0.704774 "Belajar secara online". Dampak negative belajar secara online jika pembelajaran diterapkan secara sinkronous atau langsung dimana permasalahan ada pada perbedaan waktu misalnya, berikutnya adalah kendala dan keterbatasan biaya untuk online, sering terjadinya miss komunikasi antara sipemberi materi dengan si pembelajrnya dikarenakan dibutuhkan komunikasi 2 arah antara tutor dengan mahasiswanya jika menemukan maslah atau kendala yang dihadapai agar cepat respon dan mengatasikendali miss informasi, tidak fokus terhadap materi yang diajarkan dikarenakan tergangu konsentrasi lain secara langsung maupun tidak. Sisi fositif belajar online di UT yang menerapkan sistem asinkronous memudahkan mahasiswa mendapat respon meskipun tidak secara langsung. Belajar online sangan dibutuhkan mahasiswa dalam memahami materi bahan ajar. Selain hemat tempat, hemat biaya, hemat waktu perjalanan, praktis dan ekonomis dalam belajar via daring ini yang dapat diakses diamana saja dan kapan saja. Indikator ini menjadi pilihan asosiasi merek UT terhadap belajar online yang membenak difikiran konsumenya.

Berikutnya adalah pada indikator dengan nilai tertinggi A7 0.710987 yang menyatakan "Tidak ada Drop out ". Hal ini mejadi pilihan yang paling diminati oleh para pelangganya karena dapat cuti kapan saja yang tidak terbatasi dan registrasi kapan saja sehingga memjadi lebih fleksibel, selain itu di UT juga tidak ada skrisi dan hanya ada Tugas Akhir Program sebagai penggantinya untuk meliha kompetensi mahasiswa terhadap materi-materi matakuliah keahlianya dan sesuai dengan indikator BA2. 729399 "Produk akademiknya banyak pilihan". Hal lain diperkuat dengan nilai indikator tinggi pada A8 0.692120 "Tidak ada skripsi".

Selanjutnya pada BA1 0.747017 "UT Palangkaraya mudah dikenal”, untuk daerah tertentu dikarenakan ditempat tersebut tidak ada pesaing PJJ selain UT sehingga hanya UT yang lebih dikenal dan menjadi Top of Mind sama dengan pada indikator BA6 60.602183 "Merek UT Palangkaraya mudah diingat difikiran pertama dibenak" dan BI1 0.674121 "Logo UT Palangkaraya mudah diingat", dan BI2 0.759854 "UT Palangkaraya Mudah dikenali", dengan keterkenalanya dan pengalaman serta informasi positifnya sehingga itu mnejadi "Brand UT Palangkaraya menarik" BI4 0.656564.

Sistem administrasi pendukung kegiatan ditunjang dengan sarana dan prasarana pendukung yang canggih dan terkini serta akuran dalam penggunanya membuat layanan kepada pelanggan terpuaskan, hal ini menajdi komponen 
dengan nilai tertinggi untu indikator sebesar P1 0.822121 dan para ptugas pelayanan mahsiswa sangat mebantu mahsiswa dalam memberi informasi lain untuk mendukung kegiatan kemahsiswaan sesuai dengan nilai kedua tertinggi sebesar P4 0.765981. forum komunikasidan informasi juga didapat mahasiswa untuk mengikuti berita atau informasi kekinian dan membuka forum baik yang sifatnya akademik maupun non akademik, hal ini didukung oleh pernyataan mahasiswa terhadap loyalitasnya kepada UT dan berkenaan dengan hal tersebut membuat mahasiswa tidak terkendala dengan biaya jika hasilnya seimbang dengan kepuasan layanan yang diberikan L6 0.833553

Tabel Korelasi variabel laten

\begin{tabular}{|c|c|c|c|c|c|}
\hline & Asosiasi & Brand Awarness & Brand Image & Kualitas & Loyalitas \\
\hline Asosiasi & 1.000000 & & & & \\
\hline Brand Awarness & 0.327167 & 1.000000 & & & \\
\hline Brand Image & 0.542219 & 0.676286 & 1.000000 & & \\
\hline Kualitas & 0.433416 & 0.446996 & 0.566994 & 1.000000 & \\
\hline Loyalitas & 0.401253 & 0.443366 & 0.396499 & 0.392685 & 1.000000 \\
\hline
\end{tabular}

Tabel Average Variance Extracted

\begin{tabular}{|c|c|c|}
\hline & AVE & Akar AVE \\
\hline Asosiasi & 0.348701 & 0.590509 \\
\hline Brand Awarness & 0.351512 & 0.592884 \\
\hline Brand Image & 0.465442 & 0.682233 \\
\hline Kualitas & 0.505940 & 0.711294 \\
\hline Loyalitas & 0.580574 & 0.761954 \\
\hline
\end{tabular}

Berdasarkan kedua tabel diatas terlihat bahwa korelasi maksimal konstrak Asosiasi, brand awareness, kualitas dan Loyalitas Mahasiswa Terhadap Merek UPBJJ-UT Palangkaraya dengan konstrak lainnya adalah pada Kualitas terhadap brand image sebesar 0.566994, sedangkan nilai akar AVE-nya adalah 0.711294. Korelasi maksimal konstrak lainya adalah brand image terhadap brand awareness sebesar 0.676286 dengan nilai akar AVE-nya 0.682233 konstrak lainnya adalah Loyalitas 0.1, sedangkan nilai akar AVE-nya adalah 0.761954. Hal ini berarti nilai akar AVE untuk variabel Popularitas UT dan Loyalitas mahasiswa memiliki angka diatas korelasi variabel masing-masing sehingga dianggap memiliki discriminant validity. Sedangkan untuk variabel laten Asosiasi Merek UT memiliki nilai akar AVE dibawah nilai korelasi variable latennya

Tabel Composite Realibility 


\begin{tabular}{|c|c|}
\hline & Composite Reliability \\
\hline Asosiasi & 0.836217 \\
\hline Brand Awarness & 0.791416 \\
\hline Brand Image & 0.837010 \\
\hline Kualitas & 0.834623 \\
\hline Loyalitas & 0.801159 \\
\hline
\end{tabular}

Pada tabel composit Reabilitas menunjukan bahwa nilai tertinggi dari 0.7 adalah pada Asosiasi sebesar 0.836217, diikuti Brand image 0.837010, Kualitas 0.834623 dan yang terakhir sebesar 0.801159 pada variabel Loyalitas.

Berdasarkan hasil olahan data, menunjukkan semua indikator-indikator memiliki nilai t-statistiknya > 1.96, yang berarti bahwa semua indikator tersebut mempunyai nilai yang signifikan. Nilai terbesar pada indikator Brand awareness A2 dengan nilai tertinggi 16.120321 "varian Produk akademik program studi". Varian merupakan pilihan yang akan diambil calon konsumen ketika mempertimbangkan apa yang diinginkan sesuai keinginan pasar dan kesesuian lingkup pekerjaannya. Berikutnya adalah komponen P1 dengan nilai tertinggi 23.923621 Sistem registrasi canggih, akurat dan terkini”. Pada persepsi kualitas yaitu penguatan pada infrastruktuk teknologi informasi yang mumpuni yang dapat membantu dengan cepat proses kinerja ".Brand Asosiasi berikutnya adalah Persepsi Kualitas P4 dengan nilai sedang 21.228227 "Petugas pelma membantu mahasiswa dalam memberi informasi lain". Hal ini berkaitan dengan pelayanan prima untuk memuaskan konsumen, petugas selalu berempati kepada pelangganya dan peningkatan kinerjanya selalu ditingkatkan.

Tabel Path Coefficients

\begin{tabular}{|c|c|c|c|c|c|}
\hline & $\begin{array}{c}\text { Original } \\
\text { Sample (O) }\end{array}$ & $\begin{array}{c}\text { Sample Mean } \\
(\mathbf{M})\end{array}$ & $\begin{array}{c}\text { Standard } \\
\text { Deviation } \\
\text { (STDEV) }\end{array}$ & $\begin{array}{c}\text { Standard Error } \\
\text { (STERR) }\end{array}$ & $\begin{array}{c}\text { T Statistics } \\
\text { (|O/STERR/) }\end{array}$ \\
\hline $\begin{array}{c}\text { Brand Image -> } \\
\text { Asosiasi }\end{array}$ & 0.542219 & 0.554723 & 0.050603 & 0.050603 & 10.715180 \\
\hline $\begin{array}{c}\text { Brand Image -> } \\
\text { Brand Awarness }\end{array}$ & 0.676286 & 0.688073 & 0.053062 & 0.053062 & 12.745171 \\
\hline $\begin{array}{c}\text { Brand Image -> } \\
\text { Kualitas }\end{array}$ & 0.566994 & 0.578823 & 0.057474 & 0.057474 & 9.865272 \\
\hline $\begin{array}{c}\text { Brand Image -> } \\
\text { Loyalitas }\end{array}$ & 0.396499 & 0.410436 & 0.070223 & 0.070223 & 5.646275 \\
\hline
\end{tabular}

Berdasarkan tabel Path Coefficients dapat dilihat bahwa tiga parameter jalur hubungan yang menjadi hipotesa pada penelitian ini bernilai t-statistiknya $>1.96$ yang menunjukkan signifikansi pengaruh antar variabel laten sebagai berikut : 
1. Pengaruh Brand Image terhadap Brand Awarness sebesar 12.745171, nilai ini lebih besar dari nilai t-tabel 1,98 untuk level signifikan 0.05 (5\%).

2. Brand image berpengaruh signifikan terhadap Asosiasi Berdasarkan tabel diatas, nilai t-statistik 10.715180 , nilai ini lebih besar dari nilai t-tabel 1,98 untuk level signifikan $0.05(5 \%)$.

3. Brand image berpengaruh signifikan terhadap Kualitas Berdasarkan tabel 8, nilai t-statistik 9.865272, nilai ini lebih besar dari nilai t-tabel 1,98 untuk level signifikan 0.05 (5\%).

4. Pengaruh Brand Image terhadap Loyalitas sebesar 5.646275, nilai ini lebih besar dari nilai t-tabel 1,98 untuk level signifikan 0.05 (5\%).

Tabel R-square

\begin{tabular}{|c|c|}
\hline & R Square \\
\hline Asosiasi & 0.294001 \\
\hline Brand Awarness & 0.457362 \\
\hline Kualitas & 0.321482 \\
\hline Loyalitas & 0.157211 \\
\hline Brand Image & \\
\hline
\end{tabular}

\section{KESIMPULAN DAN SARAN}

Pengujian terhadap inner model dilakukan dengan melihat nilai R-square yang merupakan uji goodnessfit model sebagai berikut:

Tabel R-square menunjukan nilai untuk varibel laten Brand Awarness didapatkan nilai sebesar 0.457362. hal ini menunjukan bahwa variabel laten 0.457362 berpengaruh sebesar $45.73 \%$ terhadap Brand Image. Untuk variable laten Kualitas berpengaruh terhadap Brand image sebesar

Nilai suatu merek merupakan hal : $32,14 \%$. kepercayaan konsumen kepada institusi konsisten dan menjadi alasan bagi konsumen untuk melakukan pembelian ulang. Brand image UT dimata mahasiswa mudah di ingat terutama logo UT namun untuk yang bukan pelanggan tidak tahu mengerti tentang logo tersebut.. Brand dan logo UT desainya menarik dan penuh manfaat sehingga menjadi identitas yang berbeda dengan perguruan tinggi disekitar Palangkaraya. Brand awareness merupakan kemampuan calon pembeli dan pelanggan dalam mengingat suatu produk atau jasa pendidikan tinggi dalam mengenali sebuah merek sebagai salah satu kekuatan identitas diri produk dan jasa. Brand awareness UT palangkaraya UT mudah dikenali, produk-produk akademik terutama Program Studinya banyak pilihan. Dari sisi layanan terus dioptimalkan dengan pelayanan prima cepat dan terkomputerisasi, unggul dalam pengalaman penyelenggaraan PTJ, pengelolaan akademik UT palangkaraya dapat dipercaya dan menjadi Top of mind dalam benak mahasiswanya Loyalitas dari suatu merek merupakan gambaran dari keterkaitan pelanggan dalam sebuah merek, ukuran tersebut dapat mempengaruhi pemikiran konsumen untuk dalam pemilihan produk atau jasa. UT yang mempunyai basis pelanggan loyalitas mereknya yang tinggi sampai pada daerahdaerah terpencil yang sulit dijangkau yang ada di UPBJJ-UT, dari sisi pemasaran UT dapat mempertahankan pelanggannya dengan biaya yang tidak mahal untuk mendapatkan calon-calon mahasiswa yang baru dan dapat menarik minat calon pembeli untuk mencoba dan memberikan keyakinan tentang produk UT. Persepsi kualitas yang baik dapat membantu UT dalam mengoptimalkan efesiensi 
dan efektifitas dalam sosialisasi promosi dan edukasi publik yang terkait terhadap keputusan pembelian produk UT. Persepsi ini juga dapat memgaruhi penentuan posisi brand UT dalam persaingan terutama dalam penetuan harga yang optimal registrasi awal dan ulang. Harga yang tidak terlalu mahal ditunjang kualitas yang baik dapat mempertimbangkan kesan positif persepsi kualitas. UT mempunyai kesan persepsi asosiasi mereknya mudah diucapkan. Kemadirian dalam perkuliahan menjadi asosiasi yang paling membenak difikiran konsumenya dilanjutkan dengan dapat belajar online, kemudahan kuliah melalui online yang dapat menghemat biaya dan waktu belajarnya lebih fleksibel

Saran Brand UT hanya membenak kepada mahsiswa saja perlu di ada inovasi-inovasi untuk dapat memperkenalkan UT sampai kepelosok-pelosok begitu juga brand awareness UT dari sisi layanan yang terkomputerisasi yang banyak mengalami kendala jaringan dan dibutuhkan kerjasama dengan vendorvendor dibidang IT untuk memperkuat jaringan internet sampai ketingkat pedesaan. Loyalitas mahasiswa pada bisa pada tingkatkan layanan UPBJJ yang mudah dijangkau mahasiswa, namun untuk tinggat Pokjar terkadang mahasiswa tidak memperoleh informasi yang optimal tentang layanan UT sehingga mahasiswa berfikir untuk melakukan pembelian ulang/registasi ulang. Dari sisi kualitas terutama bahan ajar, tutorial dan ujian perlu ditingkatkan. Pengiriman bahan ajar yang terlambat membuat tingkat kepercayaan mahasiswa menurun dan berisiko terhadap keberlangsungan belajarnya karena sumber baku utama mahasiswa dalam mengikuti ujian dan tutorial. Kepercayaan merek harus melekat kepada mahasiswa UT agar mereka tidak berpindah ke merek lain karena tingginya tingkat persaingan PTJJ selain UT yang harus diterima UT sebagai peluang, ancaman, kesempatan dan kelemahan yang harus dibenahi untuk melawan kompetitornya.

\section{DAFTAR PUSTAKA}

Aaker, D. 1997. Manajemen Ekuitas Merek: Memanfaatkan Nilai dari Suatu Merek. Mitra Utama. Jakarta.

Chadchadapom Pukkaew 2013. Assessment of the Effectiveness of Internet Based Distance Learning through the VClass e Education Platform. Asian Institute of Technology Thailand. Jounal. Vol 14

Durianto, D dan Sijintak. 2001. Strategi Menaklukkan Pasar Melalui Riset Ekuitas dan Perilaku Merek. PT Gramedia Pustaka Umum. Jakarta.

Garcia. 2016. Risk assessment and periodontal prevention in primary care. Journal of bussines \& Science Commerce Vol III doi.10.1111.prd.12124

Epy P I, Ely S.U, Emmy I. 2007. Pengaruh Ekuitas Merek Berbasis Pelanggan Telkomnet Instan Terhadap Minat Pembelian Telkomnet Speedy. Proceeding PESAT (Psikologi, Ekonomi, Sastra, Arsitek \& Sipil). Universitas Gunadarma. 21-22 Agustus 2007.

Fayrene, C dan G C Lee. 2011. Customer-Based Brand Equity : A Literature Review. Malaysia. Researchersworld Journal of Arts Science \& Commerce Vol II.

Fraser, James W. 2003. Personal versus nonpersonal sources of brand information:An Examination of their influence on brand equity in a 
Business-to-businessmarket. A Dessertation submitted to The WH. Wayne Huizenga School of Business and Entrepreneurship Doctoral Programs, Nova Southeastern University.

Gaffar, Vanessa 2007. CRM dan MPR Hotel. Alfabeta: Bandung.)

Keller, Kevin Lane 2001a, "Building Customer-Based Brand Equity”, Marketing Management, July/August.

Kotler, P \& Keller, Kevin L. 2007. Manajemen Pemasaran. Jilid I, Edisi 12. P.T. Indeks Kelompok Gramedia. Jakarta.

Peraturan Menteri Pendidikan dan Kebudayaan Republik Indonesia No.24 Tahun 2012 tentang Penyelenggaraan Pendidikan Jarak Jauh Pada Pendidikan Tinggi

Rangkuti Freddy 2008, Measuring customer satisfaction - Teknik mengukur dan strategi meningkatkan kepuaan pelanggan. Jakarta: Penerbit PT Gramedia Pustaka Utama.

Rangkuti, Freddy. 2004. The Power of brand: Teknik mengelola brand equity dan strategi pengembangan merek plus analisis kasus dengan SPSS. Jakarta: PT Gramedia Pustaka 